\title{
New host and locality record of Parapharyngodon japonicus (Nematoda: Oxyuroidea) from the Egyptian changeable lizard Agama mutabilis (Agamidae): A light and scanning electron microscopy
}

\author{
K. MORSY ${ }^{1,2 *}$, M. AL-KAHTANI' ${ }^{1}$ A. SHATI ${ }^{1}$, A. EL-KOTT ${ }^{1,3}$, R. ABDEL-GABER ${ }^{2,4}$, M. FOL $^{2}$ \\ 1Department of Biology, College of Science, King Khalid University, Abha, Saudi Arabia, ${ }^{*} E-m a l i:$ rewaida@sci.cu.edu.eg; \\ ${ }^{2}$ Department of Zoology, Faculty of Science, Cairo University, Cairo, Egypt; ${ }^{3}$ Department of Zoology, Faculty of Science, \\ Damanhour University, Damanhour, Egypt; ‘Department of Zoology, College of Science, King Saud University, Riyadh, Saudi Arabia
}

Article info

Received October 26, 2018 Accepted November 28, 2018

\section{Summary}

Parapharyngodon (Oxyurida) is a lizard gastrointestinal nematode parasite with a life cycle including lizards as main hosts. However, some species are known to parasitize anurans. In the present study, P. japonicus isolated from the large intestine of the Egyptian changeable lizard, Agama mutabilis was described and illustrated. Forty five specimens of these animals were collected from south Sinai desert, Egypt during the period from May to September 2017. After necropsy, the body was opened by a longitudinal incision from vent to throat, and the gastrointestinal tract was removed. The esophagus, stomach, small and large intestines were examined separately for helminthes. The recovered nematodes were examined by light and scanning electron microscopy. Thirty six specimens $(80.0 \%)$ were found to be naturally infected. The parasite was robust with prominent cuticular transverse annulations. Mouth surrounded by three bilobed lips, each with tiny labial papillae. Three pairs of caudal papillae were observed in male worms; 1 pair precloacal, 1 pair sublateral in cloacal opening line, 1 pair in proximal region of caudal appendage on its narrowed point. The posterior extremity beard dorsally directed caudal appendages. Females were with a conical posterior end terminated at a terminal spike. Ovaries reached esophageal isthmus but not wrapped around corpus. The parasite recorded was compared morphologically and morphometrically with the most similar species, it was found that it was most similar to $P$. japonicus with new host and locality records.

Keywords: Parapharyngodon japonicas; Nematoda; Agama mutabilis; Agamidae; light and scanning electron microscopic study

\section{Introduction}

The taxonomic status and validity of the genus Parapharyngodon have been questioned almost since its proposal by Chatterji (1933). Baylis (1936) considered it to be a synonym of the genus Thelandros Wedl (1861) (see Adamson, 1981; Adamson \& Nasher, 1984; Bursey \& Goldberg 1999, 2005). Later on, Freitas (1957) reinstated the genus Parapharyngodon which was accepted by several authors (Skrjabin et al., 1960; Baru \& Coy-Otero, 1969; Baru, 1973; Sharpilo, 1976; Baker, 1987; Castazo-Fernan- dez et al., 1987; Ashour et al., 1994; Bursey \& Goldberg, 2007a). Adamson (1981) re-established Parapharyngodon based on dietary habits of the host, morphology of the male genital cone and female tail and eggs. Males of Parapharyngodon spp. lack conical-shaped genital area and accessory piece. They have mammilliform papillae surrounding the more-or-less terminal anus and sub-terminal dorsally directed tail. Whereas males of Thelandros have a genital cone with pendulant papillae outside this cone, an accessory piece as well as terminal posteriorly directed tail is present in some species (Bursey et al., 2013; Pereira et al.,

\footnotetext{
${ }^{*}$ - corresponding author
} 
2017). Females of Parapharyngodon spp. possess a conical tail terminated in a short stout spike, eggs with sub-terminal operculum in the early stages of cleavage when released (Bursey et al., 2004; Anjum et al., 2013). Females of Thelandros have various tail morphologies, eggs with a terminal operculum larvated when released (Bursey et al., 2013; Pereira et al., 2017). More than 40 well described species are assigned to the genus Parapharyngodon according to Bursey and Goldberg (2007a,b) and Gupta et al. (2009). The Egyptian changeable lizard, Agama mutabilis Merrem (1820) is widespread across northern Africa, occurring from Western Sahara, Mauritania and Morocco east to Egypt and Sudan. This is an active predator exhibits a diurnal behavior and insectivorous including beetles, caterpillars and ants in diets and in some instances it has been known to eat large migratory locusts as they pass through its habitat. The present study reports the finding of $P$. japonicus in a new host, Agama mutabilis and locality, Egypt, including detailed morphological and morphometric characterization of this species using light and scanning electron microscopy (SEM).

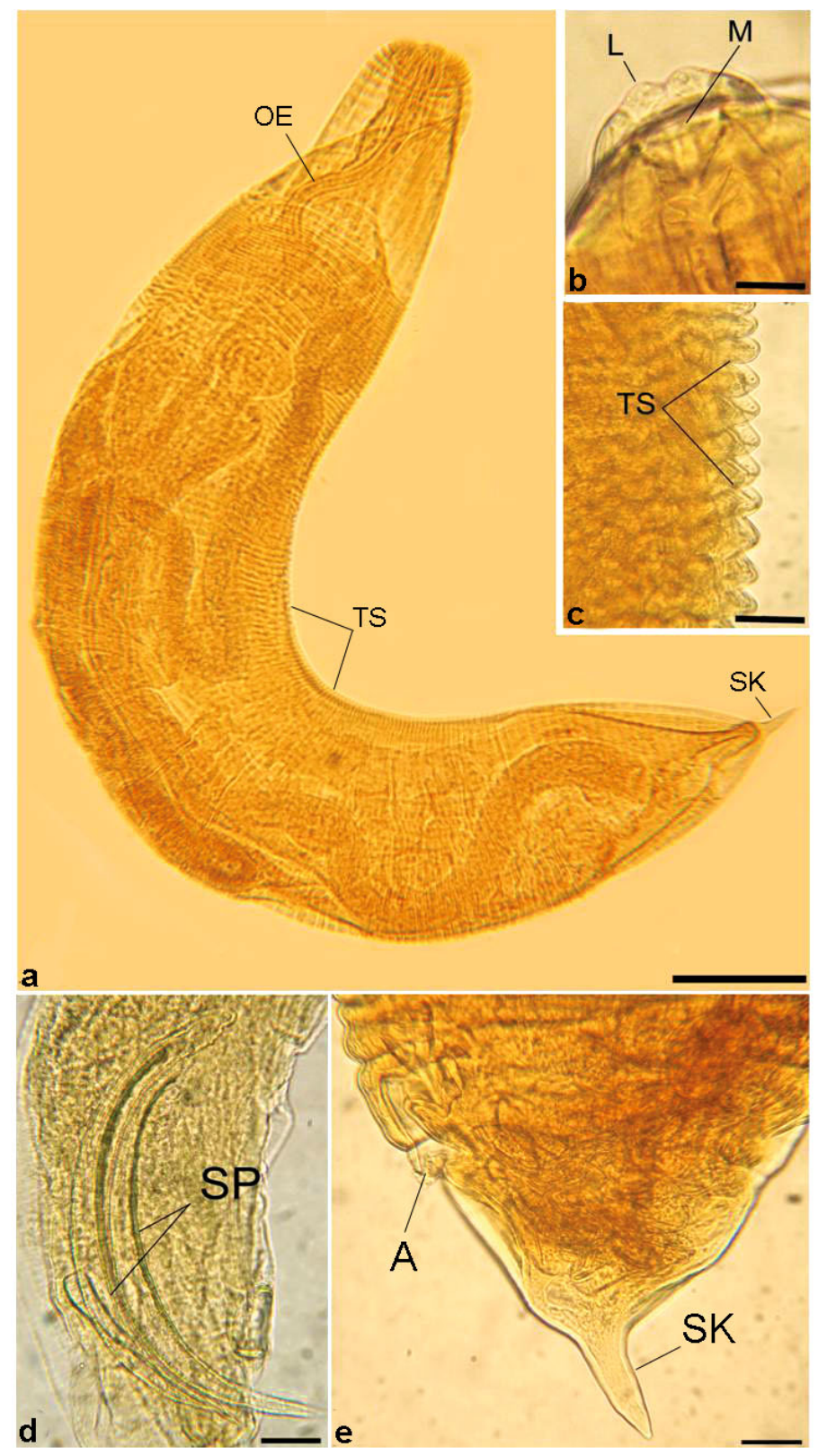

Fig. 1. (A - E): Photomicrographs of $P$. japonicus showing: A - Females, lateral view with terminal spike (SK), TS transverse cuticle striations. B - Details of the cephalic end, mouth opening (M) surrounded by three bi-lobed lips. C - Transverse cuticle striations (TS). D - Posterior end of male with two spicules (SP). E - Posterior end of female terminated at a caudal spike (SK). Scale bars: $A=300 \mu \mathrm{m} ; B, C=10 \mu \mathrm{m} ; D=100 \mu \mathrm{m} ; E=50 \mu \mathrm{m}$. 


\section{Materials and Methods}

Forty-five specimens of the mean snout-vents Agama mutabilis (length up to $9.4 \mathrm{~cm}$ ) were collected by hand or noose from South Sinai desert, Egypt during the period from May to September 2017. Animals were subjected to euthanasia using $20 \%$ benzocaine gel (Anbesol, Pfizer, Inc., New York). Each specimen was subsequently necropsied and all organs were examined for helminthes using a ZEISS Compact Greenough stereomicroscope (Model Stemi 305). All animal procedures were carried out according to the regulatory laws regarding experimental Animal Ethics Committee. Nematode worms were isolated from host intestines, heat fixed in $10 \%$ neutral buffered formalin for 15 min and then preserved in $70 \%$ ethanol in $5 \%$ glycerol solution to avoid sudden drying. Finally, samples were transferred to lactophenol for clearance. The prepared samples were examined using differential interference contrast (DIC) light microscopy with digital image analysis system (analysis auto 5.0). Drawings were made with the aid of a camera lucida. Measurements were in micrometer unless otherwise stated. For SEM, samples were fixed in $4 \%$ glutaraldehyde in $0.1 \mathrm{M}$ sodium cacodylate buffer ( $\mathrm{pH} 7.4)$, washed in the same buffer, and dehydrated in a graded alcohol series. Samples were then processed in a critical point drier "Bomer-900" with freon 13, sputter-coated with gold-palladium in a Technics Hummer $\mathrm{V}$, and finally examined with a Jeol scanning electron microscope (Model JSM7610F).

\section{Ethical Approval and/or Informed Consent}

All animal procedures were carried out according to the regulatory laws regarding experimental Animal Ethics and Use Committee.

\section{Results}

Thirty six out of $45(80.0 \%)$ specimens of the Egyptian changeable lizard, A. mutabilis were infected with nematode parasites isolated from their intestines. Worms were examined morphologically by light and SEM.

\section{Parapharyngodon japonicus Houttuyn (1782)}

Description based on 13 specimens (Figs. 1-3): Robust cylindrical nematodes with prominent cuticle annulations from beginning of the esophagus to the anal opening. Oral opening was triangular, surrounded by three bilobed lips. Each lobe beard tiny labial papillae. Buccal capsule absent. Sexual dimorphism evident, females larger and more robust than males. Lateral alae present in males, but absent in females. Males without caudal alae, caudal filament subterminal and directed dorsally. Females with conical tail terminated in a short stout spike.

Male: Small fusiform nematodes measured $1735-2986$ (2280 \pm 10) $\mu \mathrm{m}$ long, $385-490(438 \pm 11) \mu \mathrm{m}$ wide at the level of the excretory pore. Lateral alae began at the level of esophageal isthmus. Total esophagus length $290-460 \mu \mathrm{m}(388 \pm 7)$. Bulb was

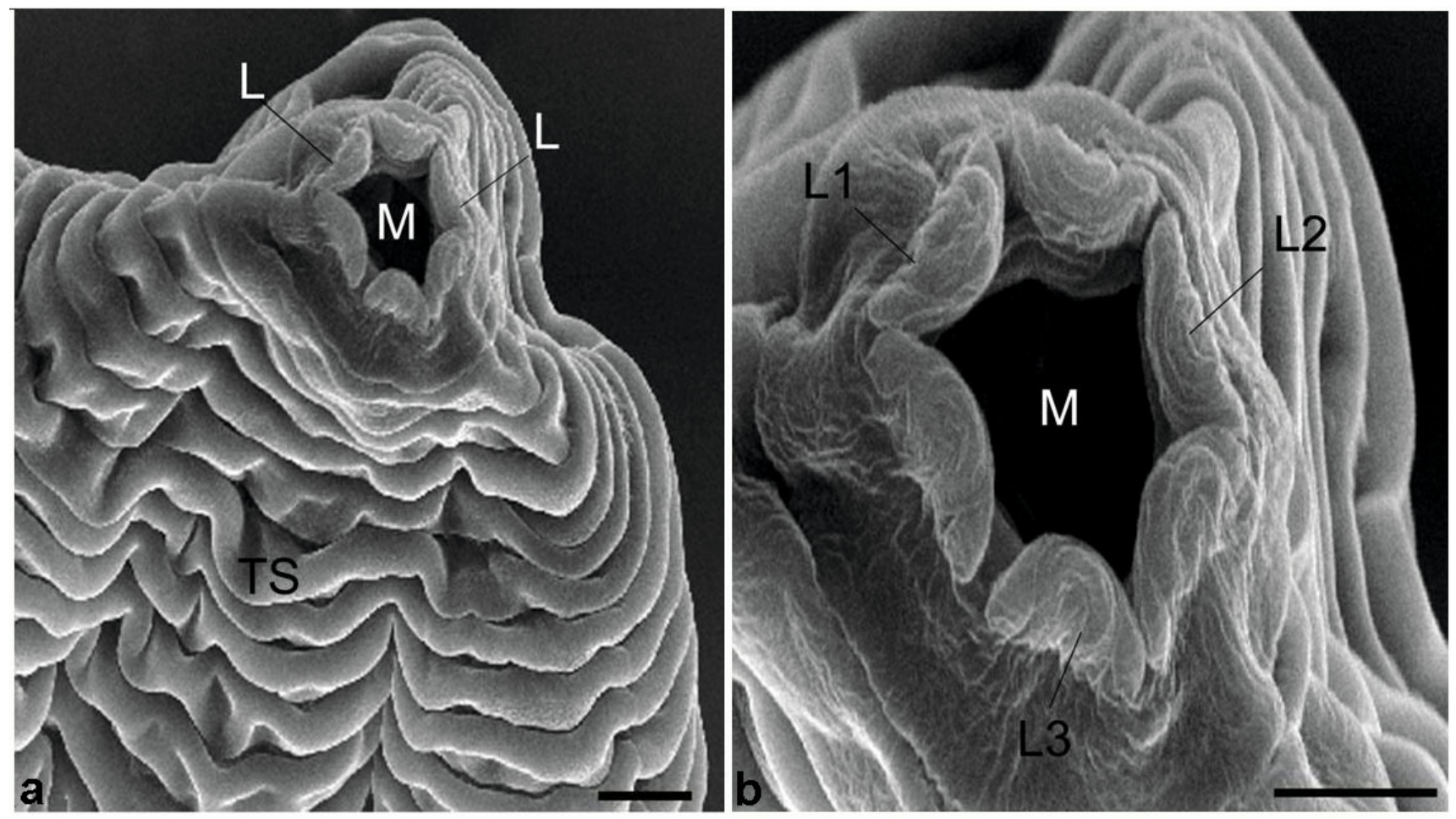

Fig. 2. (A, B): Scanning electron micrographs showing apical views of the cephalic end, L symbolized for the three bilobed lips (L1, L2, L3) surrounding mouth (M); TS for transverse cuticle striations. Scale bar $=10 \mu \mathrm{m}$. 

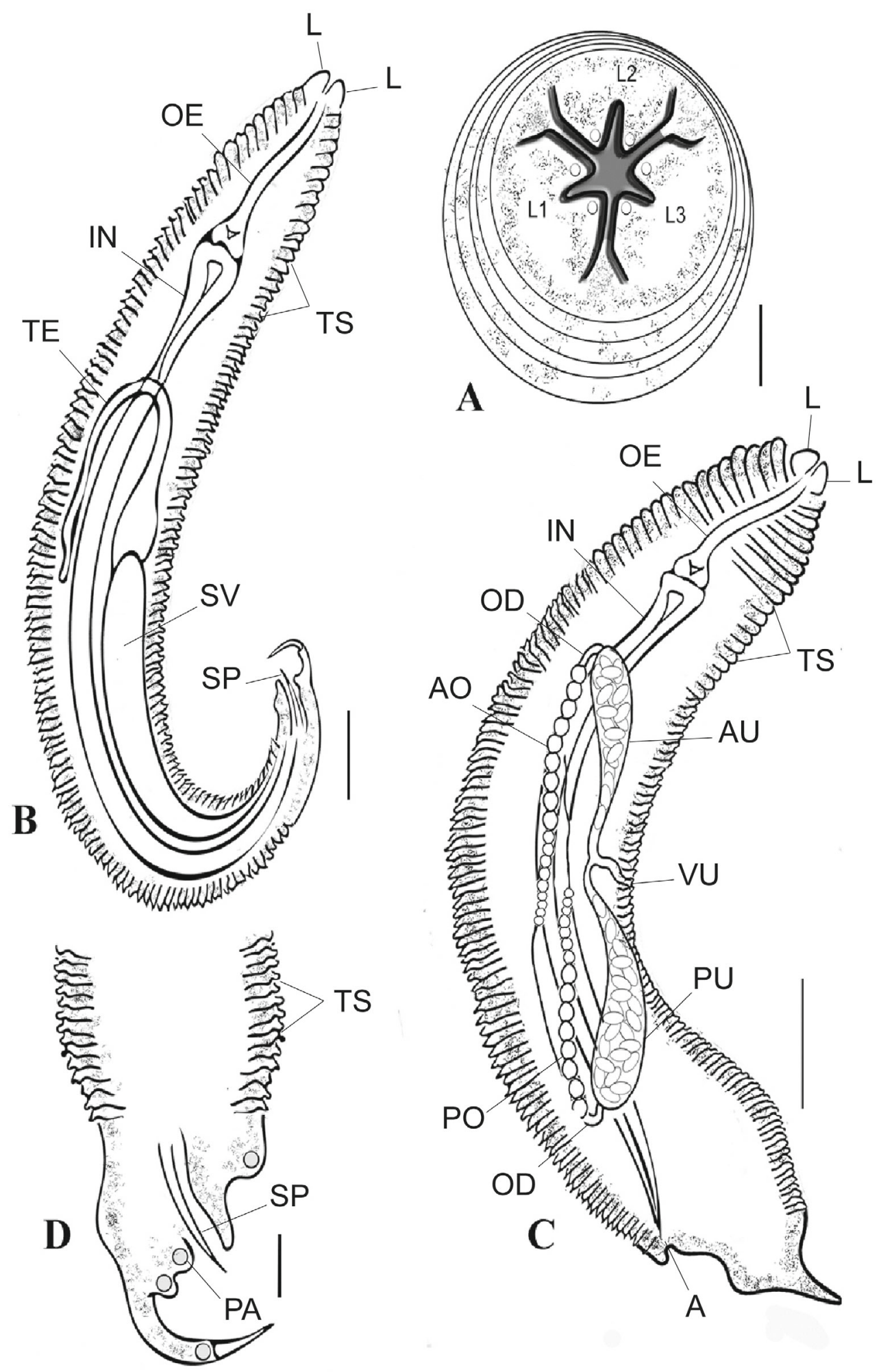

Fig. 3. Line drawings of $P$. japonicus. A, cephalic end of paratype female, apical view. B, Holotype male, lateral view. C, paratype female, lateral view. D, Posterior end of male, lateral view. L lips; OE oesophagus; IN intestine; TS transverse striations; TE testis; SV seminal vesicle; SP spicule; AO anterior ovary; PO posterior ovary; OD oviduct; AU anterior uterus; PU posterior uterus; A anus; PA caudal papillae. Scale bars: $A=10 \mu \mathrm{m} ; B=200 \mu \mathrm{m} ; C=300 \mu \mathrm{m} ; \mathrm{D}=100 \mu \mathrm{m}$. 
$\|M\| M \| M$

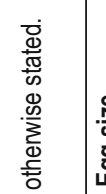

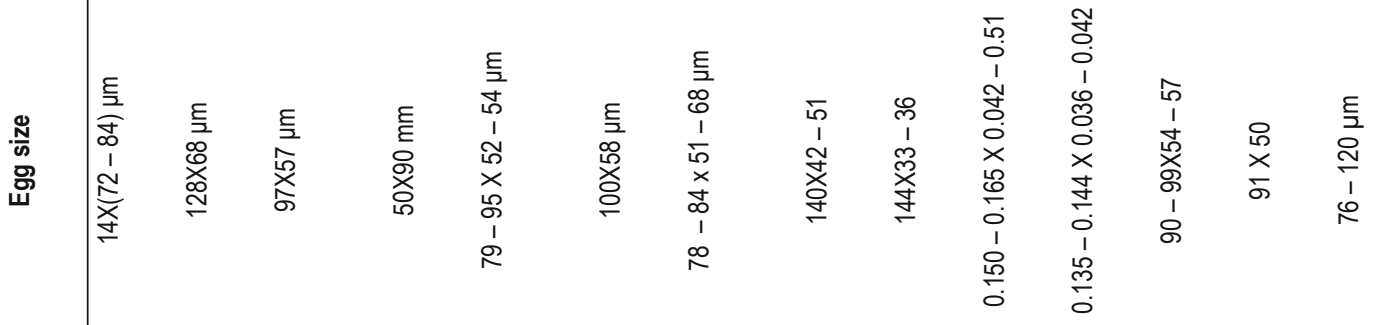

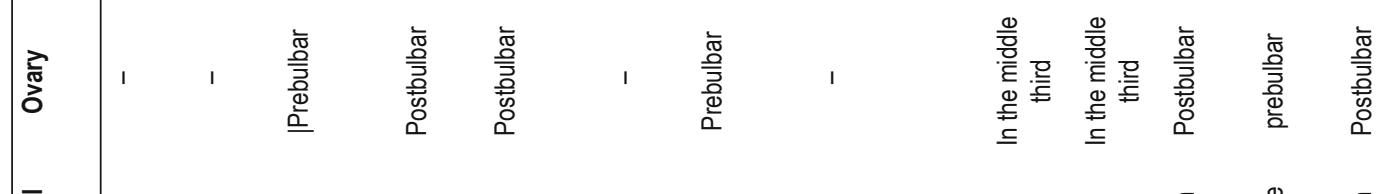

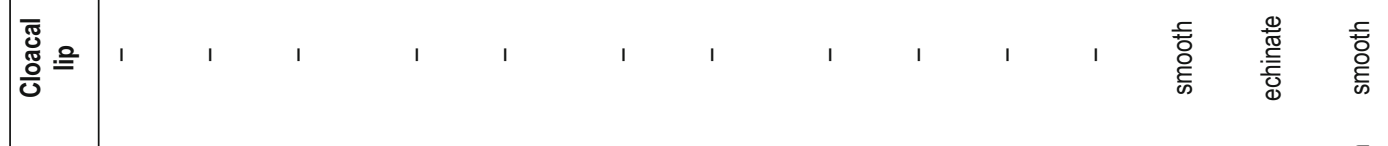

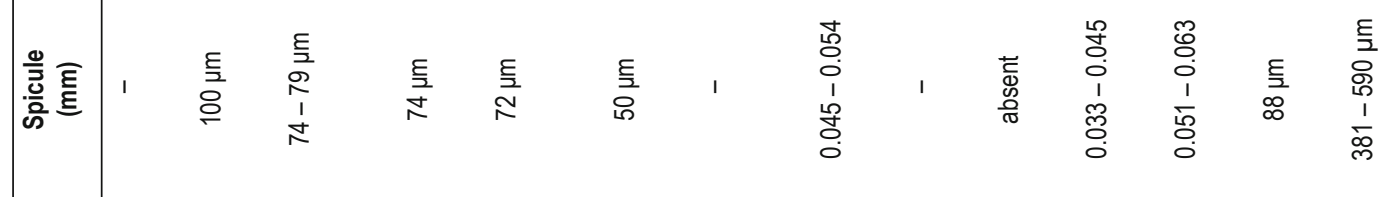

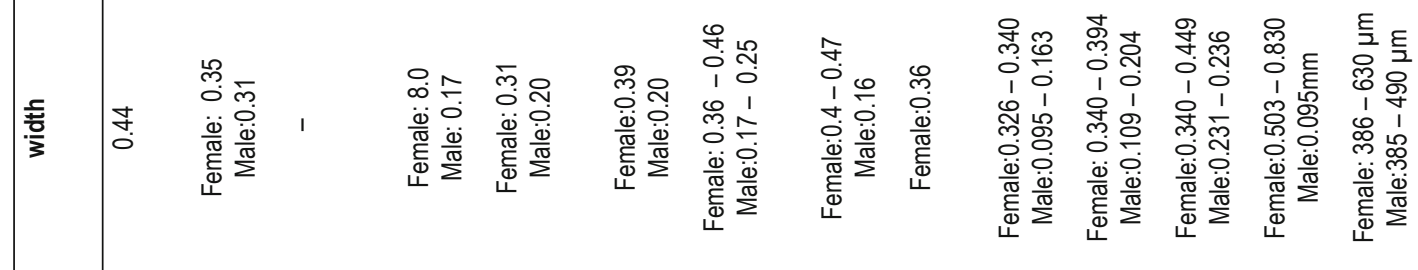

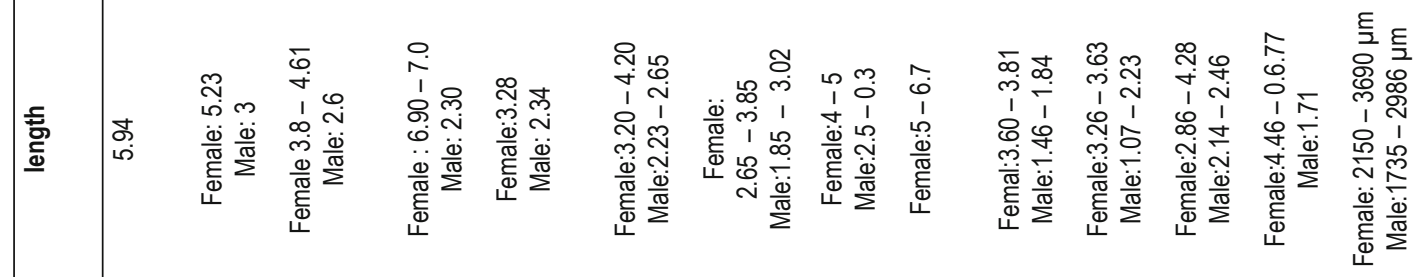

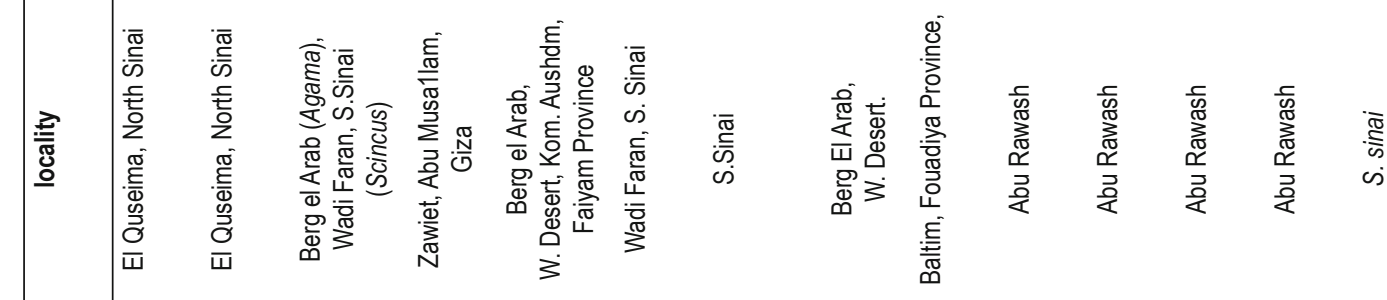

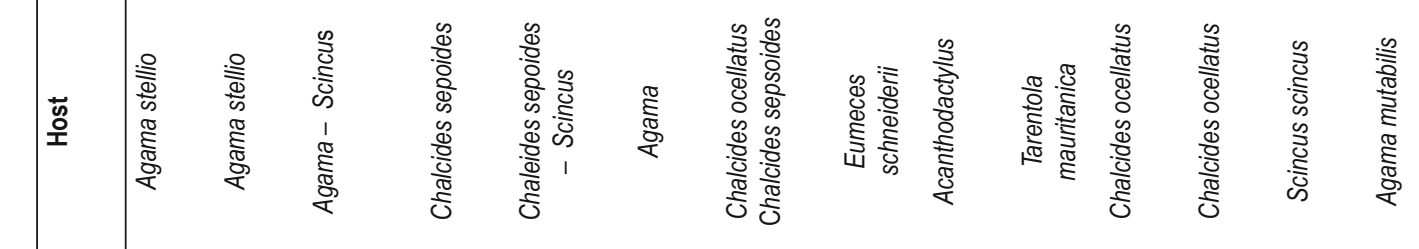

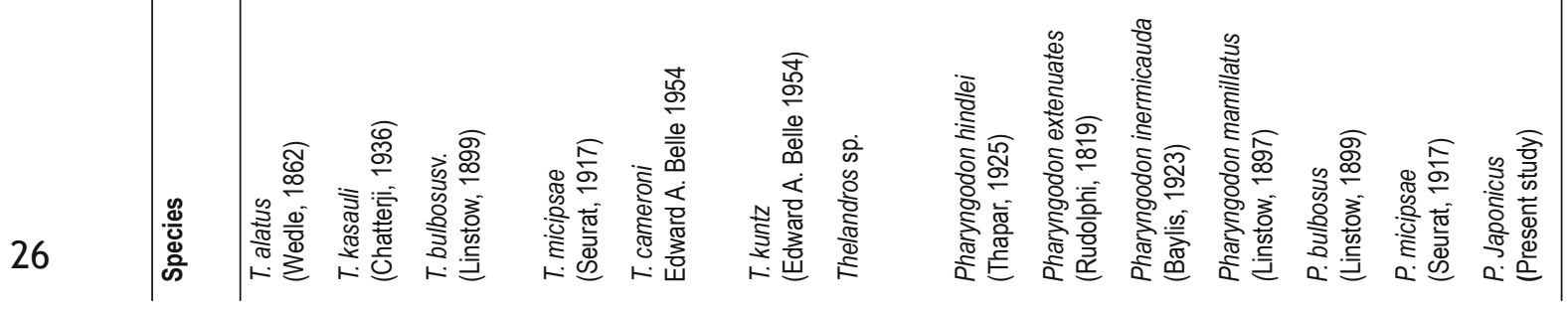


$96-161(140 \pm 6) \mu \mathrm{m}$ long and $65-105(86 \pm 5) \mu \mathrm{m}$ wide. Nerve ring and excretory pore were $60-118(70 \pm 9) \mu \mathrm{m}$ and $40-76$ $(46 \pm 6) \mu \mathrm{m}$ from the anterior end respectively. Testis reflexed posteriorly behind esophagus and the vas deferens separated from testis by a narrow tube. Three pairs of caudal papillae; 1 pair precloacal, 1 sublateral pair in cloacal opening line, 1 pair in proximal region of caudal appendage on its narrowed point. Spicules were $381-590(550 \pm 11) \mu m$ long. Posterior extremity of the body beard dorsally directed caudal appendages, terminated at a thin tip, $18-23 \mu \mathrm{m}(20 \pm 5)$ long.

Female: Body length $2150-3690(2450 \pm 17) \mu \mathrm{m}$ long x $386-630$ $\mu \mathrm{m}(510 \pm 12)$ wide at the level of vulva. Esophagus length was

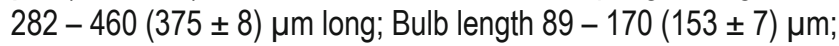
bulb width $85-120(96 \pm 10) \mu \mathrm{m}$. Nerve ring and the excretory pore were at $64-110(81 \pm 10) \mu \mathrm{m}$ and $42-86(56 \pm 7) \mu \mathrm{m}$ from the anterior end respectively. Uteri were Amphidelphic and divergent; the anterior uterus directed anteriorly while the posterior uterus was posteriorly directed and joined at the mid body. Ovaries reached esophageal isthmus but not wrapped around corpus. Eggs were oval, slightly flattened, thin-shelled and with subterminal operculum. Asymmetrical eggs extracted from ovijector in the early stages of cleavage. The posterior end of female was conical with terminal stout spike $76-120(90 \pm 13) \mu \mathrm{m}$ long.

Taxonomic Summary

Species: Parapharyngodon japonicus Houttuyn (1782)

Host: Agama mutabilis (Family: Agamidae)

Infection Site: Small intestine.

Locality: South Sinai, Egypt.

Prevalence: 36 out of $45(80.0 \%)$ specimens were infected

Deposition: Permanent slides of paratype female and holotype male were deposited at the Parasitology Division, Zoology Department Museum, Faculty of Science, Cairo University, Egypt.

\section{Discussion}

The nematode fauna of Egyptian reptiles has received little attention in recent years. The only studies include those of Seurat (1917), Baylis (1923) and Moravec et al. (1987); they described several species of nematodes from African reptiles, mostly of the genera Agama and Scincus (Table 1). The recorded species in the present study was assigned to the genus Parapharyngodon according to the key published by Bursey and Goldberg (1999) where species of Parapharyngodon are distinguished on the basis of the pattern of caudal papillae, morphology of the anterior cloacal lip, the location of the ovary, and geographical distribution. Worldwide, there are currently 83 nominal species have been assigned to Parapharyngodon, with sufficient morphological features for both male and female nematodes (Bursey \& Goldberg, 2015; Ramallo et al., 2016). The parasite recorded herein can be differentiated from Thelandros sp. based on egg development during posture and the posterior end morphology in both sexes (Bursey \& Goldberg, 2005). Parapharyngodon sp. males do not have a conical-shaped genital area, or an accessory piece. They have mammilliform papillae and a dorsal subterminal tail. Males of Thelandros sp. have a conical-shaped genital area with papillae disposed outside this cone (Bursey \& Goldberg, 1999; Bursey et al., 2013). Females of Parapharyngodon sp. generally have a cone shaped tail with a thick pointed end, like a spike, eggs with a subterminal operculum that are un-cleaved, or in early stages of cleavage when released. In contrast, Thelandros sp. females have diverse tail morphology, eggs with terminal operculum, larvae are fully developed when they are released (Ramallo et al., 2016; Bursey et al., 2013; Velarde-Aguilar et al., 2015). Parapharyngodon japonicus recovered from Onychodactylus japonicus by Bursey and Goldberg (1999) in Japan is most similar to the present nematode isolated. Where both share the presence of postbulbar ovarian coils, the tail of female terminated at a small spike, eggs are thin-walled and the anterior cloacal lip is smooth. They resemble $P$. tyche in the presence of smooth anterior cloacal lip, ovary is postbulbar, and the eggs are thin-walled and oval in outline, the female spike is small and uterus is thick-walled. They differ from each other in that the spicules in $P$. japonicus male is half the length of those in $P$. tyche, and the lateral alae of $P$. japonicus end abruptly about $80 \mu \mathrm{m}$ anterior to the cloaca, whereas in $P$. tyche, the lateral alae continue to the end of the body. All of the nematode species of family Pharyngodonidae reported from lizards in Egypt were compared (Table 1); two of them are from the same genus, P. bulbosus (Linstow, 1899) by Moravec et al. (1987) from Chalcides ocellatus in Egypt and P. micipsae. P. bulbosus differ from the present species in that tails of females which is conical without distinct caudal spike and ovarian coils not reaching anterior level of esophagus; while $P$. micipsae differ by the presence of postbulbar ovaries in females and their anterior ends forming prominent coils around the base of esophagus while their males have 4 pairs of caudal papillae and echinate anterior cloacal lip. Moravec et al. (1987) isolated a nematode $P$. aegyptiacus which further has since been transferred to Skrjabinodon inglis by Moravec and Barus (1990).

\section{Acknowledgements}

The authors extend their appreciation to the Deanship of Scientific Research at King Khalid University for funding this work through Research group Project under grant number (R.G.P.1-56 -40).

\section{Conflict of Interest}

The authors declare that they have no conflict of interest.

\section{References}

Adamson, M.L. (1981): Parapharyngodon osteopili n. sp. (Pharyngodonidae: Oxyuroidea) and a revision of Parapharyngodon and Thelandros. Syst. Parasitol., 3: 105 - 117. DOI: 10.1007/ BF00012216 
Adamson, M.L., Nasher, A.K. (1984): Pharyngodonids (Oxyuroidea: Nematoda) of Agama adramitana in Saudi Arabia with notes on Parapharyngodon. Can. J. Zool., 62: 2600 - 2609

Anjum, N.R., BuRsey, R.C. (2013): A new species of Parapharyngodon (Nematoda: Pharyngodonidae) from the yellow-bellied house gecko, Hemidactylus flaviviridis (Squamata: Gekkonidae), from Dehradun (Uttarakhand), India. Comp. Parasitol., 80(2): 251 258. DOI: $10.1654 / 4628.1$

Ashour, A.A., Wanas, M.Q., Salama, M.M.I., GafaAr, N.A. (1994): Scanning electron microscopy observations on Parapharyngodon bulbosus (Linstow, 1899) (Nematoda: Pharyngodonidae) from Egyptian Chalcides ocellatus. J. Egypt. Soc. Parasitol., 24: 585 $-590$

BAKER, M.R. (1987): Synopsis of the Nematoda parasitic in amphibians and reptiles. Memorial University of Newfoundland, Occasional Papers in Biology, 11: 1 - 325

BARU, V. (1973): Some remarks on the Neotropical species of the genera Parapharyngodon and Batracholandros (Oxyuridae). Folia Parasitol., 20: 131 - 139

Baru, V., Coy-Otero, A. (1969): Nematodes del genero Parapharyngodon Chatterji, 1933 (Oxyuridae), en Cuba [Nematodes of the genus Parapharyngodon Chatterji, 1933 (Oxyuridae), in Cuba]. Torreia, 7: 1 - 10

BAYLIS, H.A. (1923): Report on a collection of parasitic nematodes mainly from Egypt. Part I. Ascaridae and Heterakidae. Part II. Oxyuridae Part III. Camallanidae etc., with a note on prostmayria and an appendix on Acanthocephala. Parasitology, 15 (1): 1 - 3, 14 $-23,24-38$

BAyLIS, H.A. (1936): Nematoda. I. Ascaridoidea and Strongyloidea. The fauna of British India. Taylor and Francis, London, U.K, 408 pp. BuRsey, C.R., Brooks, D.R. (2004): Parapharyngodon duniae n.sp. (Nematoda: Pharyngodonidae) in Phrynohyas venolosa (Anura: Hulidae) from the Area de Conservacion Guanacaste, Guanacaste, Costa Rica. J. Parasitol., 90: 137 - 139

Bursey, C.R., Drake, M., Cole, R., Sterner, M., Pinckney, R., ZIEGER, U. (2013): New species of Parapharyngodon (Nematoda: Pharyngodonidae) in Rhinella marina (Anura: Bufonidae) from Grenada, West Indies. J. Parasitol., 99: 475 - 479. DOI: 10.1645/ GE-3235.1

BuRsey, C.R., Goldberg, S.R. (1999): Parapharyngodon japonicus sp. n. (Nematoda: Pharyngodonidae) from the Japanese Clawed Salamander, Onychidactylus japonicus (Caudata: Hynobiidae), from Japan. J. Helminthol. Soc. Wash., 66: 180 - 186

BuRSEY, C.R., GoldBerg, S.R. (2005): Two new species of Pharyngodonidae (Nematoda: Oxyuroidea) and other nematodes in Agama caudospina (Squamata: Agamidae) from Kenya, Africa. J. Parasitol., 91: 591 - 599. DOI: 10.1645/GE-3421

Bursey, C.R., Goldberg, S.R. (2007a): A new species of Parapharyngodon (Nematoda: Pharyngodonidae) and other helminths in Typhlosaurus lineatus (Squamata: Scincidae), from southern Africa. J. Vet. Res., 74: $143-147$

Bursey, C.R., Goldberg, S.R. (2007b): New species of Para- pharyngodon (Nematoda: Pharyngodonidae) and other helminths in Petrosaurus repens and P. thalassinus (Squamata: Phrynosomatidae) from Baja California del Sur, Mexico. Southwest. Nat., 52: $243-250$

BuRSEY, C.R., Goldberg, S.R. (2015): Description of a new species of Parapharyngodon (Nematoda: Pharyngodonidae) from Mexico with a list of current species and key to species from the Panamanian region. J. Parasitol., 101: 374 - 381. DOI: 10.1645/13-460.1 Castazo-Fernandez, C., Zapatero-Ramos, L.M., Solera-Puertas, M.A., GonzÁlez-Santiago, P.M. (1987): Descripción de Parapharyngodon lilfordi n. sp. (Oxyuroidea, Pharyngodonidae) en Podarcislilfordi (Reptilia, Lacertidae) de las Islas Baleares [Description of Parapharyngodon lilfordi n. sp. (Oxyuroidea, Pharyngodonidae) in Podarcis lilfordi (Reptilia, Lacertidae) of the Balearic Islands]. Rev. Ibér. de Parasitol., 47: 275 - 281

ChatterJ,, R.C. (1933): On a new nematode, Parapharyngodon maplestoni gen. nov., sp. nov., from a Burmese lizard. Ann. Trop. Med. Parasitol., 27: 131 - 134

FREITAS, J.F.T. (1957): Sôbreosgêneros Thelandros Wedl, 1862 e Parapharyngodon Chatterji, 1933, com descric, ão de Parapharyngodon alvarengai sp. n. (Nematoda, Oxyuroidea) [About genera Thelandros Wedl, 1862 and Parapharyngodon Chatterji, 1933, with a description of Parapharyngodon alvarengai sp. $n$. (Nematoda, Oxyuroidea)]. Mem Inst Oswaldo Cruz., 55: 21 - 45 GUPTA, N., M. BASHKAR, D. K. GUPTA. (2009): Gastrointestinal invasion in Hemidactylus flaviridis with a new species of Parapharyngodon (Oxyuroidea: Pharyngodonidae). Zootaxa, 2169:39 - 51. DOI: $10.1654 / 4628.1$

LINSTow, O.V. (1899): Nematodenaus der Berliner Zoologischen Sammlung [Nematodes from the Berlin Zoological Collection]. Mitteilungenaus der zoologischen Sammlung des Museums Naturkunde in Berlin, 1: 3 - 289

Merrem, B. (1820): Versuch eines Systems der Amphibien I (Tentamen Systematis Amphibiorum) [Attempt of a system of amphibians I (Tentamen Systematis Amphibiorum)]. J. C. Kriegeri, Marburg, $191 \mathrm{pp}$.

MoRAVEC, F., Barus, V. (1990): Some nematode parasites from amphibians and reptiles from Zambia and Uganda. Acta soc. Zool. Bohemosolv., 54: 177 - 192

Moravec, F., Baruš, V., RYšavÝ, B. (1987): On parasitic nematodes of the families Heterakidae and Pharyngodonidae from reptiles in Egypt. Folia Parasitol., 34: 269 - 280

Pereira, F.B., Campião, M.K., José, L.L., Luiz, E.R.T. (2017): Parapharyngodon hugoi n. sp., a new nematode (Oxyuroidea: Pharyngodonidae) of the tree frog Trachycephalus typhonius (Linnaeus) from the Brazilian Pantanal, including a key to the congeners from amphibians of the American continent. Syst. Parasitol., 94 (5): 599 - 607. DOI: 10.1007/s11230-017-9725-5

Ramallo, G., Bursey, C., Castillo, G., Acosta, J.C. (2016): New species of Parapharyngodon (Nematoda: Pharyngodonidae) in Phymaturus spp. (Iguania: Liolaemidae) from Argentina. Acta Parasitol., 61: 461 - 465. DOI: 10.1515/ap-2016-0062 
SEURAT, L.G. (1917): Sur les oxyures des sauriens du Nordafricain [On the pinworms of North African saurians]. Arch. Zool. Exp. Gen., 56: $401-444$

SharPlLO, C.P. (1976): Parasitic Worms of the Reptilian Fauna of the USSR: Systematics, Chorology, Biology. Naukova Dumka, Moscow, $287 \mathrm{pp}$.

SkRjabin, K.I., ShiKhobalova, N.P., Lagodovskaya, E.A. (1960): OKsiuratishivotnykh i cheloveka. Chast I. Oxyuroidea.Osnovy Nematodologii VIII [Parasites of human. Part I. Oxyuroida. Basics of
Nematodology VIII]. Izdatel'stvo Akademiya Nauk SSSR, Moskva, $557 \mathrm{pp}$.

Velarde-Agullar, M.G., Mata-López, R., Guillén-Hernández, S., LEÓN-RĖGAGNON, V. (2015): Parapharyngodon n. spp. (Nematoda: Pharyngodonidae) parasites of hylid frogs from Mexico and review of species included in the genus. J. Parasitol., 101: $212-230$. DOI: 10.1645/13-328.1

WEDL, K. (1861): Zur Helminth en fauna Egyptens [Helminth fauna of Egypt]. Sitzungsberichte Mathematisch-Naturwissenschaftliche Fakultät Akademie der Wissenschaften 44: 463 - 482 